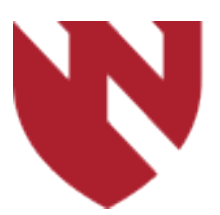

December 2019

\title{
An Immediate Weight Bearing Protocol versus Stress Radiography to Determine Ankle Stability in Patients with Isolated SER Distal Fibula Fractures
}

\author{
Phillip Thomas \\ University of Nebraska Medical Center \\ Leonid Grossman \\ University of Nebraska Medical Center \\ Justin Siebler \\ University of Nebraska Medical Center \\ Ivan Tarkin \\ University of Nebraska Medical Center \\ Lori Reed \\ University of Nebraska Medical Center
}

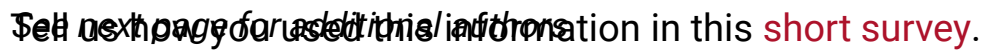

Follow this and additional works at: https://digitalcommons.unmc.edu/gmerj

Part of the Higher Education Commons, and the Medicine and Health Sciences Commons

\section{Recommended Citation}

Thomas, P., Grossman, L., Siebler, J., Tarkin, I., Reed, L., Lyden, L., , Mormino, M. An Immediate Weight Bearing Protocol versus Stress Radiography to Determine Ankle Stability in Patients with Isolated SER Distal Fibula Fractures. Graduate Medical Education Research Journal. 2019 Dec 13; 1(1). https://digitalcommons.unmc.edu/gmerj/vol1/iss1/39

This Conference Proceeding is brought to you for free and open access by DigitalCommons@UNMC. It has been accepted for inclusion in Graduate Medical Education Research Journal by an authorized editor of DigitalCommons@UNMC.For more information, please contact digitalcommons@unmc.edu. 


\section{An Immediate Weight Bearing Protocol versus Stress Radiography to Determine Ankle Stability in Patients with Isolated SER Distal Fibula Fractures}

\section{Creative Commons License}

\section{(c) (i) $\Theta($}

This work is licensed under a Creative Commons Attribution-Noncommercial-No Derivative Works 4.0 License.

Authors

Phillip Thomas, Leonid Grossman, Justin Siebler, Ivan Tarkin, Lori Reed, Liz Lyden, and Matthew Mormino 
be collected at clinic visits up to 90 days postoperatively. Data from each stage will be compared to assess the effectiveness of the guidelines in providing adequate analgesia while minimizing opioid prescriptions.

Results \& Conclusions: Pending further data collection.

https://doi.org/10.32873/unmc.dc.gmerj.1.1.038

\section{An Immediate Weight Bearing Protocol versus Stress Radiography to Determine Ankle Stability in Patients with Isolated SER Distal Fibula Fractures \\ Phillip Thomas, Leonid Grossman, Justin Siebler, Ivan Tarkin, Lori Reed, Liz Lyden, Matthew Mormino}

Mentor: Matthew Mormino

Program: Orthopaedic Surgery

Purpose: To compare stress radiographs with weight bearing radiographs in the acutely injured ankle and determine if stress views may be unnecessary and ultimately lead to unnecessary surgical intervention.

To determine if patients allowed to weight bear will show similar results radiographically and clinically to the current gold standard stress views.

Methods: A prospective study will be conducted with UNMC, UPMC \& Mississippi
Centers with 200 total subjects enrolled. Every subject with isolated fibular fracture will have stress view $\mathrm{x}$-rays taken in the ED. They will then be placed in a CAM boot and follow up in clinic $\sim 7$ days later. Weight bearing x-rays will be obtained at follow up and UNMC \& UPMC will use weight bearing $\mathrm{x}$-rays to determine operative intervention. Mississippi will use only stress views to determine operative intervention

Results \& Conclusions: Collecting data. Currently nine subjects had medial clear space widening $>4 \mathrm{~mm}$ on gold standard stress views. However, $0 / 9$ at most recent follow up have had MCS $>4 \mathrm{~mm}$ and therefore none have shown signs indicative of a need for surgery.

Hypothesis: The gold standard of stress views for isolated fibular fractures may be misrepresenting the common biomechanical stressors carried through the ankle as part of activities of daily living. Therefore, we believe it is possible that many isolated fibular fractures are being unnecessarily treated with operative intervention.

https://doi.org/10.32873/unmc.dc.gmerj.1.1.039

\section{Effect of Crystalloid Infusion Rate in a Noncompressible Hemorrhage Model} Ujwal Yanala, Jason Johanning, Iraklis Pipinos, Gustavo Larsen, William Velander, Mark Carlson

Mentor: Mark Carlson

Program: General Surgery

Purpose: To determine the effect of fluid administration rate on survival, vital signs, blood loss, and laboratory parameters in a porcine model of noncompressible hemorrhage.

Methods: Twenty domestic swine (barrow, age 3 months, 32-36 kg) underwent hemitransection of left lateral liver lobe without treatment. Incision was temporarily closed immediately after injury. At 60's after injury, lactated ringers solution was begun at either 150 or $20 \mathrm{~mL} / \mathrm{min}$ IV (rapid and slow group, respectively, $\mathrm{N}=10$ each); maximum volume was capped at $100 \mathrm{~mL} / \mathrm{kg}$. Both groups were monitored for 60 or $180 \mathrm{~min}$.

Results: Pre-injury physiological parameters did not differ between the groups. Survival after one hour in both the groups was $60 \%$; no further death occurred in the slow group with observation out to $180 \mathrm{~min}$. Necropsy demonstrated that an equivalent number of portal vein and hepatic vein branches had been transected in each group. There were no significant differences between groups for heart rate, temperature, total volume of LR infused, or liver weight.

Conclusion: Although the two groups were not directly comparable (no formal randomization; longer observation time in the slow group), this study demonstrated that in a porcine model of noncompressible truncal hemorrhage, intravenous crystalloid resuscitation with a relatively slow infusion rate $(20 \mathrm{~mL} / \mathrm{min})$ produced less blood loss and an improved laboratory profile (hemoglobin and protime). This study supports the U.S. military's recent adoption of a "hypotensive resuscitation" protocol for warfighters injured in the field, which dictates that fluid resuscitation of an injured warfighter with hemorrhagic shock should be restricted until the subject arrives at a forward surgical unit.

https://doi.org/10.32873/unmc.dc.gmerj.1.1.040

\section{Renal Salvage after Stent Graft Placement after Acute Renal Artery Occlusion with Prolonged Time of Ischemia \\ Yue Gao, Dimitrios Miserlis, Matthew Longo, Nitin Garg}

Mentor: Nitin Garg

Program: General Surgery

Purpose: To describe a patient with acute renal artery occlusion (RAO) who underwent successful revascularization procedure, after experiencing prolonged ischemic period, which resulted in successful retrieval of renal function.
Case Report: A middle-aged patient with past history left renal artery stenosis and stent graft placement presented with symptoms of chest pain, shortness of breath, and flank pain. The patient was admitted to Intensive Care Unit with diagnosis of multi-organ failure and subsequent anuria that led to initiation of hemodialysis. Computed tomography angiography (CTA) demonstrated chronic aortic occlusion along with bilateral proximal renal artery occlusion with reconstitution of the mid to distal renal arteries via collateralization. Patient underwent angioplasty with bilateral renal artery stent-graft placement and successful revascularization of proximal renal arteries. Post-operatively, renal function and urine output improved, and the patient was able 